\title{
Policymaking, Comitology, and the Balance of Power in The European Union
}

\author{
BERNARD STEUNENBERG \\ University of Twente, Emschede, The Netherlands \\ Christian Koboldt and Dieter Schmidtchen \\ Universität des Saarlandes, Saarbrücken, Germany \\ E-mail:csle@rz.uni-sb.de
}

Using simple game theory, this paper analyzes the working properties of the different procedures laid down in the comitology decision, i.e., the European Council's decision on procedures for the exercise of implementing powers conferred on the Commission. Furthermore, it addresses the question of how the balance of power is determined by this decision.

\section{Introduction}

In its decision of July 13, 1987 the Council laid down procedures for the exercise of implementing powers conferred on the Commission [see European Council (1987)]. Articles 2 and 3 of the so-called "comitology" decision officially established advisory committees, management committees, and regulatory committees. The committees, which are bodies of representatives (civil servants) from the member states, consult, but also supervise, the Commission's execution of legal acts. The principal difference between the advisory committee and the other two committees is that the management and the regulatory committees can block a measure proposed by the Commission. While not having a decision making power of their own, the latter committees act as gatekeepers. If they are in disagreement to the Commission's position, the Council will take up the matter and may overrule or just invalidate the Commission's decision. The generally accepted view is that there is the following hierarchical ordering with respect to the restrictiveness of the three procedures: the regulatory committee over the management committee, and the management committee over the advisory committee. It is

The authors want to thank Sven Berg, Manfred Holler, Ron Heiner, Lea Paterson, Daniel Rubinfeld, and Göran Skogh for helpful comments, and Ige Dekker and Torsten Stein for providing them with legal material on comitology. The usual disclaimer applies. 
worthwhile to note that the European Parliament does not play any role in the implementation phase of legal acts in the Union.

Although advisory committees, management committees, and regulatory committees have become an integral part of the European institutional structure, there is surprisingly little research about the role of such committees to be found in constitutional law and economics. Using simple game theory, this paper analyzes the working properties of the different procedures laid down in the comitology decision, outlines a concept of power, and asks how the balance of power is determined by this decision. ${ }^{1}$ As for the concept of power developed in this paper, it should be mentioned that the degree of power is determined not only by looking at the restrictions imposed by the procedural rules, i.e., the structure of decision rights, but also by recognizing the way in which players are restricted by their opponents' preferences. Whereas traditional power concepts used in economics are an outgrowth of cooperative game theory, the concept we use is based on non-cooperative games.

The paper is organized as follows. In Section II we describe policymaking in the European Union and point to ways in which the Council tries to restrict the power of the Commission in implementing European policies. In Section III we analyze current decision making procedures using a model in which the Commission may select a policy that is subject to review by a committee of representatives of the member states and the Council. Section IV examines the power of the Commission and of the Council under the different procedures. In Section V we present our main conclusions.

\section{Implementation Procedures}

In delegating implementing decisions to the Commission, the Council has to take account of the fact that the Commission already plays an important role in the legislative process. In all current legislative procedures of the European Union (EU), the Commission has the exclusive power of initiative. ${ }^{2}$ To prevent the Commission from becoming too powerful by having unrestricted discretion at the implementation stage, the Council delegates some of its implementing powers to the Commission under the condition that specific decision making procedures have to be used. Although these procedures vary across different European legal acts, three different types can be distinguished, partly based on the comitology decision [see Kapteyn and VerLoren van Themaat (1990), pp. 240-247]. The first type is called the advisory committee procedure, in which a committee of representatives of the member states gives its opinion on a draft measure of the Commission. The Commission has to take this advice into account and is obliged to inform the committee of representatives about the way in which the committee's advice has affected its final policy choice. This procedure will not be analyzed further in this paper as it does not grant any decision making power to players other than the Commission.

\footnotetext{
${ }^{1}$ To the best of our knowledge, our contribution can be seen as one of the first attempts to analyze the implementation procedures that govern policymaking in the European Union using an economic approach and, more specifically, the tools of non-cooperative game theory.

${ }^{2}$ See Cooter and Drexl (1994), Tsebelis (1994), and Steunenberg (1994b) for more detailed analyses of the legislative procedures in the European Union. Note that Tsebelis assumes that the European Parliament had conditional agenda-setting power under the cooperation procedure. However, this assumption is not in accordance with the Treaty or the way in which the Treaty is applied in practice, as Moser (1995) explains.
} 
The second type is the management committee procedure. In this procedure the Commission is assisted by a committee of representatives of the member states, which gives its opinion on the Commission proposal by qualified majority. ${ }^{3}$ If the committee of representatives agrees with the Commission proposal or remains divided, the Commission proposal will be implemented. If the committee of representatives adopts a different view, the Commission reports its proposal to the Council. ${ }^{4}$ The Council may only take a decision that deviates from the Commission proposal by qualified majority. If the Council agrees with or does not respond to the proposal, the Commission is allowed to implement its proposal.

The third procedure is the regulatory committee procedure. In this procedure, the Commission submits its proposal again to a committee of representatives. This committee of representatives has to give its opinion on the Commission proposal by qualified majority rule. If the committee of representatives proposes a policy that deviates from the Commission proposal, or when the committee of representatives does not reach a decision, the Commission has to submit its proposal to the Council. A divided committee of representatives in this procedure means that the Commission proposal has to be submitted to the Council. With regard to decision making in the Council, two variants of this procedure can be distinguished. In both variants, the Council may amend the Commission proposal by qualified majority. In variant (a), which will be called the amendment procedure, the Commission proposal will be adopted if the Council does not decide otherwise. A Council decision that deviates from the Commission proposal has to be based on a qualified majority. In variant (b), the Council additionally may veto the Commission proposal by a simple majority. This variant of the regulatory committee procedure is known as the "contrefilet" procedure. In this paper this version will be called the veto procedure.

Under the management committee procedure, the Commission has been delegated the authority to determine a new policy. The Council may deviate from this proposal only if the committee of representatives gives a negative opinion on the Commission proposal. Under the regulatory committee procedure, only if the committee of representatives gives a positive opinion on the Commission proposal can it be implemented. In all other cases, the Council may set a different policy by a qualified majority or veto the Commission proposal.

The main difference between the two variants of the regulatory committee procedure, i.e., the amendment and the veto procedure, is the voting procedure. In the amendment procedure, the Council can change the Commission proposal only if a qualified majority opts for a different point of view. If the Council fails to adopt a different view, the Commission proposal will be implemented. In the veto procedure, the Council is able to reject the Commission proposal by a simple majority in favor of the status quo ante, i.e., the situation where no policy will be implemented. In that case, the Council has to make a comparison between the Commission proposal and the status quo ante. If the Council prefers the Commission proposal to the status quo ante, it will not use its veto right.

\footnotetext{
${ }^{3}$ As provided for in Article $148(2) \mathrm{EC}$.

${ }^{4} \mathrm{At}$ this point two variants of the procedure can be distinguished which will not be discussed in this paper. In variant (a) the Commission may implement the measure if it is being discussed by the Council. In variant (b) this is not possible, and the implementation of the measure has to be deferred for a specific period of time.
} 


\section{Policymaking Under Different Arrangements}

Players, Preferences, and Decision-Making Procedures

To analyze the extent to which the Commission is bound to the Council in selecting different policy measures, a model will be used with three types of players:

(i) the members of the Council,

(ii) the members of the committee of state representatives, ${ }^{5}$ and

(iii) the Commission, which will be regarded as a unitary actor.

(See Steunenberg [1994a] for a similar model applied to policymaking in parliamentary systems.) These players are assumed to decide on some regulatory issue, which can be represented by a one-dimensional outcome $X$. The preference of a player $i$ over $X$ is represented by a function $U_{i}=U_{i}(x)$, which defines single-peaked preferences. ${ }^{6}$ The preference set of a player $i$, that is, the set of points a player strictly prefers to some point $x$, is defined as

$$
\mathscr{P}_{i}(x) \equiv\left\{y \in X \mid U_{i}(y)>\mathrm{U}_{\mathrm{i}}(x)\right\}
$$

a weak version of the preference set is $\mathscr{R}_{i}(x)$, which is defined as

$$
\mathscr{R}_{i}(x) \equiv\left\{y \in X \mid U_{i}(y) \geqslant \mathrm{U}_{\mathrm{i}}(x), y \neq x \in X\right\} .
$$

For a group of players, ${ }^{7} S$, these preference sets are defined as

$$
\mathscr{P}_{S}(x) \equiv\left\{y \in X \mid U_{i}(y)>U_{i}(x) \text { for all } i \in S\right\},
$$

and

$$
\Re_{S}(x) \equiv\left\{y \in X \mid U_{i}(y) \geqslant \mathrm{U}_{\mathbf{i}}(x) \text { for all } i \in S, y \neq x \in X\right\} .
$$

Furthermore, player $i$ 's point of indifference to a proposal $x$ will be denoted as $I(x)$.

Decisions are assumed to be made sequentially. The sequence is based on the existing procedures that specify the order in which players are allowed to make a move. Players are assumed to have complete and perfect information. This assumption implies that the preferences of players, the structure of the game, and the fact that players behave in a rational way, are assumed to be common knowledge, while for every stage of the game only one player is allowed to make a move. Second, we assume that none of the players prefers its decision to be overturned. This preference can be viewed as imposing some cost on a proposal that is not the final outcome of the decision making process. These costs are assumed to reduce the final payoff to a player. All of the implementation games we consider in the paper have a unique subgame perfect Nash equilibrium, which we take to define the outcome of the implementation game.

Qualified majority voting, which combines special majority voting and weighted majority voting, play an important role in the EU decision-making process. Under this rule, each voter may cast a specific number of votes, and a special majority is required to

\footnotetext{
${ }^{5} \mathrm{As}$ indicated, the members of these committees of representatives are civil servants from the national administrations of the member states. Depending on the policy field involved, more than one sector specialist from the same member state can be appointed to these committees. Furthermore, changes in appointments to these committees occur relatively infrequently. So, in our view, it is a priori not clear that committee members have preferences identical to those of the ministers in the Council.

${ }^{6}$ Since players have single-peaked preferences along a single dimension, the well-known median voter theorem (Black 1987, p. 18) applies if a decision has to be made on the basis of simple majority voting.

${ }^{7} \mathrm{~A}$ group of players constitutes a voting body or, as it is called in the literature, a committee (cf. Black, 1987). In this respect, the Council and the committees of representatives are committees in the technical meaning.
} 


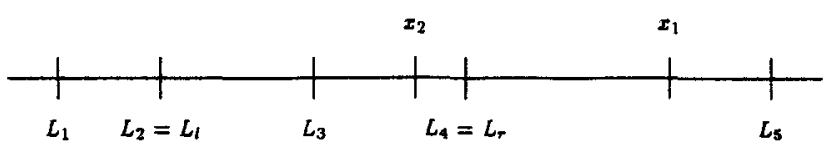

FIG. 1. Qualified majority voting in a five-member Council.

adopt a proposal. This may lead to some complications, which can be illustrated by a (hypothetical) five-member Council. In Figure $1, L_{i}$ denotes the ideal point of Council member $i$, and $L_{i}(x)$ stands for this member's point of indifference to the policy $x$. If, for instance, a two-thirds majority is needed to approve a proposal, while Council members have equivalent vote shares, member 2 or member 4 is important, since two-thirds of the ideal points in the Council are found to the right or to the left of this member including his or her own vote. So, if the initial proposal $x$ satisfies $x>L_{4}$, such as $x_{1}$ in the figure, a two-thirds majority strictly prefers an alternative proposal $y=L_{4}$ to the initial proposal $x_{1}$. Consequently, the Council will approve this alternative proposal $y$. However, if $L_{2} \leqslant x \leqslant L_{4}$, as illustrated by $x_{2}$ in the figure, the initial proposal divides the members of the Council. Some members prefer a move to the left, others to the right. But neither of them is able to form the required qualified majority against the initial proposal. In that case, the Council is not able to approve any new proposal, and $x_{2}$ will be implemented.

Under qualified majority rule each voter does not have just one vote, but instead may cast a number of votes that varies between voters. A decisive Council member, such as member 2 or member 4 in the example, has to be defined in terms of the number of each player's votes. Now, assume, without loss of generality, that $x \geqslant L_{m}$, with $L_{m}$ as the ideal point of the median Council member. ${ }^{8}$ Given some distribution of Council members along the policy dimension $X$, a Council member will be called the decisive qualified majority member, $L_{r}$, if it finds to its left the ideal points of other Council members whose vote shares constitute the smallest qualified majority, including its own vote share. This group of members, of which $r$ is the rightmost member, will be denoted as $S_{r}^{L}$. If all members are allowed to propose amendments, ${ }^{9}$ qualified majority voting yields the following outcome:

$$
y=\left\{\begin{array}{l}
L_{r} \text { for } x>L_{r} \\
x \text { for } L_{r} \geqslant x \geqslant L_{m}
\end{array}\right.
$$

If $x>L_{r}$ the preference set of group $S_{r}^{L}, P_{S_{r}^{L}}(x)$, is non-empty, and the Council is able to amend the initial proposal to $y=L_{r}$, which is the best proposal feasible to the members of $S_{r}^{L}$. If $x \leqslant L_{r}, P_{S_{r}^{L}}(x)=\varnothing$, and the Council is not able to form a qualified majority against the initial proposal $x$. In general, the Council is not able to reach a decision for initial proposals that are found between its two decisive members. These proposals form the "blocking" set for Council moves, which is defined as

\footnotetext{
${ }^{8}$ The interested reader should be able to derive the results for $x \leqslant L_{m}$, which contains strategically equivalent cases to the ones discussed in this paper.

${ }^{9}$ We assume that the Council, or, in general, any committee (in the technical sense) uses a well-ordered agenda in the following sense: First, all proposed amendments are being collected and ordered according to their deviation from the initial proposal; second, each amendment is being compared with the initial proposal in a binary vote starting with the amendment that deviates most from the initial proposal.
} 


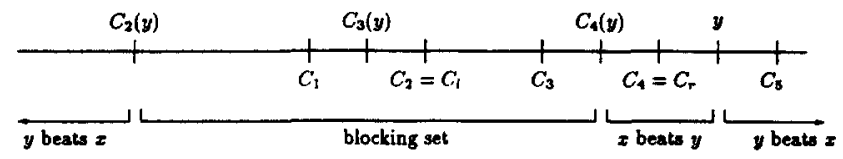

FIG. 2. Qualified majority voting in a five-member committee of representatives.

$$
M \equiv\left\{x \mid P_{S_{l}^{L}}(x)=\emptyset \text { and } P_{S_{r}^{L}}(x)=\emptyset\right\} .
$$

Initial proposals that are an element of this set, are invulnerable to amendments.

Now we want to analyze the decision that has to be made by the committee of representatives. This committee of regulatory acts as a gatekeeper, but has no rights to amend the initial proposal. Therefore, it can choose only between the initial proposal $x$ (by keeping its gates closed) and the amended proposal $y$ (which it can expect to result from opening its gates). Using qualified majority rule, proposals may exist that divide the committee of representatives: Neither the initial proposal, $x$, nor the proposed amended policy, $y$, will be preferred by a qualified majority in the committee. If the initial proposal is selected in such a way that it makes the relevant decisive committee member indifferent between both proposals (i.e., $x=C_{4}(y)$ or $x=C_{2}(y)$ in Figure 2 ), this player will not support proposal $y$, and the committee is not able to reach a decision. The proposals that will not lead to a committee decision are found in the so-called gatekeeper's "blocking" set. This set is defined as

$$
G(y) \equiv\left\{x \mid C_{l}(y) \leqslant x \leqslant C_{r}(y)\right\},
$$

with $C_{l}(y)$ and $C_{r}(y)$ as the point of indifference to $y$ of the leftmost and the rightmost decisive qualified majority committee member, respectively. For the five-member committee in Figure 2, and a subsequent proposal $y$, this set is equivalent to the interval $\left[C_{2}(y), C_{4}(y)\right]$. If, for instance, the initial proposal is $x=C_{2}$, the gatekeeping committee will be divided and cannot reach a decision. Depending on a specific EU decisionmaking procedure, a divided committee may lead to either the implementation of the Commission policy or the submission of this proposal to the Council.

\section{Management Committee Procedure}

The management committee procedure can be modeled as a game that consists of three stages. In the first stage the Commission proposes a new policy $x$. In the second stage the committee of representatives, acting as a gatekeeper, considers the policy proposed by the Commission. Only if the committee disagrees on the Commission proposal by qualified majority, is the Commission proposal submitted to the Council. In the third and last stage, the Council considers the Commission proposal and may propose a different measure, $y$, by qualified majority. Let $a$ be the Commission; $c_{i} i \in\{l, \eta\}$, is the relevant decisive qualified majority member of the committee of representatives, while $l_{i}, i \in\{l, \eta\}$, stands for the decisive qualified majority member in the Council. The game tree for this procedure is given in Figure $3 .{ }^{10}$

To solve this game, we proceed by backward induction. In the last stage, the Council will consider the Commission proposal, $x$, and determine whether sufficient support

\footnotetext{
${ }^{10}$ Note that the endnodes are labelled with the outcomes in terms of the policy that is selected rather than with the individual payoffs. These payoffs, however, can be obtained by substituting the policy outcome into each player's utility function. For example, the policy $x$ results in individual payoffs to the players equal to $\left(U_{a}(x), U_{C_{l}}(x), U_{l_{I}}(x)\right)$.
} 


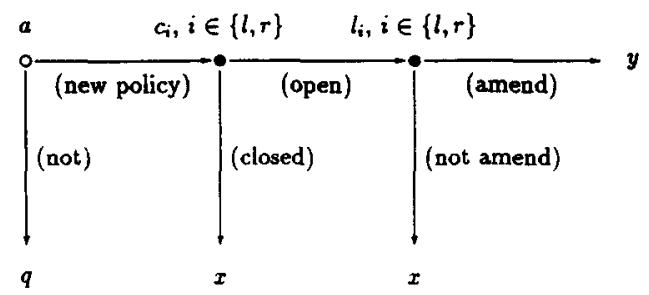

FIG. 3. Game tree for management committee procedure.

exists to select a different policy, $y$, given $x$. The Commission proposal, $x$, forms the status quo post, which will be implemented if the Council does not respond. Assume, for simplicity, that the Commission has a "progressive" preference compared to the Council, i.e., $A \geqslant L_{m}$, so $x \geqslant L_{m}$. Consequently, we can restrict our attention to $l_{r}$ as the relevant qualified majority member in the Council. The Council's response is now given by Equation 1. In the second stage, the committee of representatives has to determine whether or not it will accept the Commission proposal given the response of the Council. The committee keeps its gates closed when

(i) a qualified majority of the committee weakly prefers $x$ to $y=L_{r}{ }^{11}$

(ii) the committee cannot form a qualified majority, or

(iii) the Council cannot amend the Commission proposal and therefore will accept $\boldsymbol{x}$.

If one of these conditions is satisfied, committee behavior will not lead to the submission of the Commission proposal to the Council. ${ }^{12}$ Knowing this response, the Commission will select its best proposal such that one of these conditions is satisfied. This proposal will be the equilibrium outcome.

Proposition 1: Under the management committee procedure, the equilibrium policy $\mathrm{x}$ is the Commission's preferred point in the interval $\left[\mathrm{L}_{\mathrm{m}}, \max \left(\mathrm{L}_{\mathrm{r}}, \mathrm{G}_{\mathrm{r}}\left(\mathrm{L}_{\mathrm{r}}\right)\right]\right]^{13}$

As this result indicates, the equilibrium policy is found between the median Council member (which is used as the leftmost policy position in our analysis) and the decisive qualified majority member of the Council. A more extreme preference of the rightmost decisive committee member, $c_{r}$, increases the number of potential equilibrium policies. If $C_{F}>L_{r}$, the Commission may select a policy that the decisive committee member (weakly) prefers to the outcome of Council decision making (i.e., $y=L_{r}$ ). The most extreme policy the Commission may choose is the committee member's point of indifference to the Council policy, $C_{r}\left(L_{r}\right)$.

\footnotetext{
${ }^{11}$ Formally, $R_{S_{i}^{C}}\left(L_{r}\right) \neq \emptyset, i \in\{l, \eta\}$, which implies that proposals exist that are preferred to the outcome of Council decision making. In a qualified majority vote, the Council will eventually set a policy equivalent to the ideal point of its decisive member, $L_{r}$ (see Equation 1). Furthermore, recall that $S_{i}^{C}$ is a qualified majority coalition of gatekeeping committee members with $i$ as its leftmost or rightmost member. Note that the committee might be able to form a qualified majority in favor of $y$ in two cases:

(a) if $C_{r}<L_{r}$, so $y>C_{r}$ or

(b) if $C_{l}>L_{r}$, so $y<C_{r}$

${ }^{12}$ Formally, the committee will keep its gates closed when the Commission proposal, $x$. is an element of the following set: $R_{S_{i}}\left(L_{r}\right) \cup G\left(L_{r}\right) \cup M: i \in\{l, \eta$.

${ }^{13}$ See the Appendix for a proof of all results.
} 


\section{Regulatory Committee Procedure: Amendment}

The main difference between the management and the regulatory committee procedure is that the Commission proposal has to be submitted to the Council if the committee of representatives does not reach a decision. So the amendment version of the regulatory committee procedure can be modeled as the management committee procedure with the following modification: Only if a qualified majority in the committee weakly prefers the proposal of the Commission, $x$, to the Council measure, $y$, will it keep its gates closed. This implies that the committee will accept the Commission proposal

(i) when a qualified majority of committee members weakly prefers $x$ to $y$, or

(ii) when the Council cannot amend the Commission proposal and therefore will accept $x$.

The committee will present a positive opinion on the Commission proposal if one of these conditions is satisfied. ${ }^{14}$ Knowing this response of the committee, the Commission selects its best proposal such that one of these conditions is satisfied.

PROPOSITION 2: Under the amendment version of the regulatory committee procedure, the equilibrium policy $\mathrm{x}$ is the Commission's preferred point in the interval $\left[\mathrm{L}_{\mathrm{m}}, \max \left\{\mathrm{L}_{\mathrm{r}}, \mathrm{C}_{1}\left(\mathrm{~L}_{\mathrm{r}}\right)\right\}\right]$.

In comparison to the management committee procedure, the interval from which the Commission may select its best proposal is more restrictive: Since, by definition, $C_{l}<C_{m}$, so $C_{l}\left(L_{r}\right)<C_{r}\left(L_{r}\right)$. This is the result of the fact that the Commission has to submit its proposal to the Council if the committee does not reach a decision. Consequently, the Commission can no longer propose a policy that leads to a divided committee. Only when a qualified majority in the committee prefers the Commission proposal to the Council policy, will it be able to present a positive opinion. This requirement increases the involvement of the Council and, at the same time, decreases the extent to which the Commission is able to formulate a new public policy that differs from the preferences of Council members.

\section{Regulatory Committee Procedure: Veto}

The veto version of the regulatory majority procedure provides the Council with an additional opportunity: Besides amending the Commission proposal, the Council may also reject the new proposal by simple majority. This procedure will be modeled in the following way: After the committee's decision in the second stage, the Council first decides whether or not it will veto the Commission proposal before it considers amendments. If the Council vetoes the Commission proposal, the status quo ante, $q$, will again come in to effect. The game tree ${ }^{15}$ of this game is given in Figure 4.

In the last stage, the Council will consider the Commission proposal and select $y=L_{r}$ if $x>L_{r}$ or $y=x$ if $x \leqslant L_{r}$ (see Equation 1). The median Council member, $l_{m}$, will take this response into account and use its veto only if it prefers $q$ to either $x$ or $L_{n}$ i.e., if $x$ or $L_{r}$ are not an element of the median Council member's preference set $R_{l m}(q)$. Since $L_{m} \leqslant L_{r}$ a veto will be issued when $q<L_{r}<x$, or when $q<x \leqslant L_{r}$ However, if $x$ or $L_{r}$

\footnotetext{
${ }^{14}$ Formally, the committee will keep its gates closed when the Commission makes a proposal that is an element of $R_{S f}\left(L_{r}\right) \cup M, i \in\{l, \eta$. That is, the proposal should be an element of the committee's qualified majority preference set or the blocking set for Council moves.

${ }^{15}$ See footnote 10 for the labeling of the endnodes.
} 


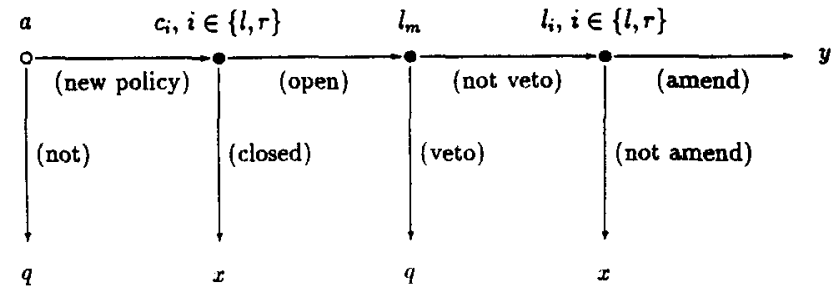

FIG. 4. Game tree for the veto version of the regulatory committee procedure.

is an element of $R_{l m}(q)$, the median Council member will not use its veto power. ${ }^{16}$ In the second stage, the committee has to decide whether or not to keep its gates closed, i.e., give a negative opinion on the Commission proposal. It will keep its gates closed when it weakly prefers $x$ to either $q$ or $y=L_{p}$, or when the Council cannot amend the Commission proposal and therefore has to accept $x$, while the proposal is not being vetoed. ${ }^{17}$ Knowing this response of the gatekeeping connmittee, the Commission selects its preferred proposal, given that this proposal will not need to be submitted to the Council.

Proposition 3: Under the veto version of the regulatory committee procedure, the equilibrium policy $\mathrm{x}$ is the Commission's preferred point in the interval

(i) $\left[\mathrm{L}_{\mathrm{m}}, \max \left(\mathrm{L}_{\mathrm{r}}, \mathrm{C}_{1}\left(\mathrm{~L}_{\mathrm{r}}\right)\right.\right.$ ) ] for $\mathrm{q} \geqslant \mathrm{L}_{\mathrm{r}}$, or

(ii) $\left[\mathrm{L}_{\mathrm{m}}, \max / \mathrm{q}, \mathrm{C}_{1}(\mathrm{q}) /\right]$ for $\mathrm{L}_{\mathrm{m}}<\mathrm{q}<\mathrm{L}_{\mathrm{r}}{ }^{18}$

Note that for $q \geqslant L_{r}$, the equilibrium outcome of the veto version is equivalent to the amendment version of the regulatory committee procedure. Only when $q<L_{n}$ does the additional veto of the Council play a role. While the Council cannot amend proposals that are found between its median member, $l_{m}$, and its decisive qualified majority member, $l_{r}$, it can object against those proposals that are not veto proof. This additional power of the Council reduces the set of proposals from which the Commission may select its policy. ${ }^{19}$ Consequently, the Commission loses some of its power, that is, the ability to set different common policies.

\section{The Balance of Power Under Different Institutional Arrangements}

The power of the European Commission (or of any other player in the implementation game) to set new policies that coincide with its own preferences is affected by the rules of the decision-making game (committee procedures) as well as by the preferences of the other players. Although ideally one might want to know how severely players are re-

\footnotetext{
${ }^{16}$ Note that, in those cases, the response of the Council is as follows: It will propose $y=L_{r}$ if $x>L_{r}$ and $q \geqslant L_{r}$ or $y=x$ if $x \leqslant L_{r}$ and $q \geqslant x$.

${ }^{17}$ Formally, the Commission proposal will not be submitted to the Council when $x \in R_{5 f}\left(L_{r}\right) \cup\left[M \cap R_{l_{m}}(q)\right]$ for $q>L_{n}$ or $x \in R_{S_{i}^{C}}(q) \cup\left[M \cap R_{l_{m}}(q)\right]$ for $q<L_{r}$

${ }^{18}$ For $q<L_{m}$, the following solution can be derived: The equilibrium policy $x$ is the Commission's preferred point in the interval

- $\left[L_{m}, \max \left[C_{l}(q), L_{m}(q)\right\}\right]$ for $L_{m}(q)<L_{r}$ or

- $\left[L_{m}, \max \left[C_{l}\left(L_{r}\right), L_{r}\right]\right.$ for $L_{m}(q) \geqslant L_{r}$

${ }^{19}$ Note that $C_{l}(q)<C_{l}\left(L_{r}\right)$ since $q<L_{r}$
} 
stricted in implementing their preferred policy, such a measure would require strong assumptions about the specific preferences of each player. Therefore, we will approximate the power of a player by measuring how close the outcomes under a given procedure, given different constellations of preferences, come to the player's ideal point.

Clearly, a player is worse off the further away from his ideal point is the outcome of an implementation game. Because the outcome of an implementation game depends on the procedure used as well as on the players' preferences, and because a procedure is used for a multitude of decisions about topics on which the players' preferences may vary, we will use the mean or expected distance between a player's ideal point and the outcomes of implementation games as a measure to illustrate the effect of the committee procedures on the players' power.

Additionally, we will consider a fictitious (or dummy) player (denoted by $d$ ) who also has preferences over the policy space that meet the same requirements as the preferences of the players, but who does not affect the outcome of the implementation game. This dummy player may be said to have no power.

To calculate the mean distance between the outcomes and the ideal points of the players under different procedures, we make the following simplifying assumptions:

- The possible ideal points of the players and the possible status quo ante are equidistant on the policy dimension, and the minimal distance between two possible ideal points is the same for all preference constellations. This minimal distance between two different ideal points is denoted by $\delta$.

- The ideal points of all decisive players (i.e., the Commission, the leftmost decisive member and the rightmost decisive member of the Committee, and the median member and the rightmost decisive member of the Council) as well as the ideal point of the dummy player may but need not differ from each other and may but need not differ from the status quo ante.

- All preferences that satisfy $A \geqslant L_{m}{ }^{20} C_{l} \leqslant C_{r}, L_{m} \leqslant L_{r}$ and $q \geqslant L_{m}$ are equally probable.

It is important to stress that this last assumption does not mean that the ideal points of the players who determine the outcome of the implementation game are distributed uniformly on a closed interval. Since we restrict our analysis to cases where the ideal point of the Commission as well as the status quo ante are not to the left of the ideal point of the median Council member, and because the ideal points of the rightmost, the median and the leftmost decisive member of a committee must not be in descending order, the assumption of equal likelihood of preference constellations that satisfy the above conditions is different from the assumption of equal probability of every possible ideal point for each player. This difference, however, does not imply any bias, because without the restrictions $A \geqslant L_{m}$ and $q \geqslant L_{m}$ the outcomes of the policy game would be strategically equivalent to those dealt with in the paper (see also note 20).

The assumption of equal likelihood of all feasible preference constellations, however, excludes correlated preferences of individual players (except of the restrictions of our analysis to cases where the ideal point of the Commission as well as the status quo ante is not less than the ideal point of the median Council member). In particular, we

\footnotetext{
${ }^{20}$ This restriction allows to use only Propositions 1 through 3 to determine the outcome of a specific procedure given a specific constellation of preferences. It is important to note that this restriction does not imply any bias, because with $A<L_{m}$ the policy games would be strategically equivalent to the games with $A \geqslant L_{m}$. This is to say that without this restriction, the number of possible preference constellations would increase, but the mean distances would remain the same, as the outcomes just mirror the outcomes given by Propositions 1 through 3.
} 
TABLE 1. Mean distance between outcome and preferred policy under different procedures

\begin{tabular}{|c|c|c|c|c|c|c|c|c|c|}
\hline \multirow[b]{2}{*}{$\mathbf{N}$} & \multicolumn{3}{|c|}{$\begin{array}{c}\text { Procedure 1: } \\
\text { management committee }\end{array}$} & \multicolumn{3}{|c|}{$\begin{array}{l}\text { Procedure 2: } \\
\text { regulatory committee } \\
\text { amendment }\end{array}$} & \multicolumn{3}{|c|}{$\begin{array}{c}\text { Procedure 3: } \\
\text { regulatory committee } \\
\text { veto }\end{array}$} \\
\hline & $\Delta_{1}$ & $\Delta_{\mathrm{I}_{\mathrm{m}}}$ & $\Delta_{\mathrm{d}}$ & $\Delta_{\mathrm{a}}$ & $\Delta_{\mathrm{l}_{\mathrm{m}}}$ & $\Delta_{\mathrm{d}}$ & $\Delta_{\mathrm{a}}$ & $\Delta_{\mathbf{l}_{\mathrm{m}}}$ & $\Delta_{\mathrm{d}}$ \\
\hline 2 & 0.11 & 0.75 & 0.86 & 0.24 & 0.62 & 0.86 & 0.35 & 0.51 & 0.86 \\
\hline 3 & 0.15 & 1.12 & 1.19 & 0.34 & 0.93 & 1.18 & 0.48 & 0.79 & 1.17 \\
\hline 4 & 0.19 & 1.49 & 1.51 & 0.43 & 1.25 & 1.49 & 0.61 & 1.06 & 1.48 \\
\hline 5 & 0.22 & 1.86 & 1.83 & 0.52 & 1.56 & 1.79 & 0.74 & 1.34 & 1.78 \\
\hline 6 & 0.26 & 2.23 & 2.15 & 0.62 & 1.86 & 2.10 & 0.88 & 1.61 & 2.08 \\
\hline 7 & 0.29 & 2.59 & 2.46 & 0.71 & 2.17 & 2.40 & 1.01 & 1.87 & 2.38 \\
\hline
\end{tabular}

abstract from cases where the group of "truly European players" (i.e., Parliament and Commission), on the one hand, and the group of "national players" (Council members and state representatives forming the committees), on the other hand, are more likely to have similar preferences within the group and divergent preferences between groups. $^{21}$

Given these simplifying assumptions, the number of feasible preference constellations (including possible status quo ante) is finite and denoted by $N$. This number depends on the length of the interval over which the ideal points are distributed. For example, given an interval of length $3 \delta$, there are four possible values that the ideal points may take, viz. some arbitrary number $x, x+\delta, x+2 \delta$, and $x+3 \delta$. In general, if the ideal points are distributed over an interval of length $n \delta$, then the number of possible values that an ideal point may take is given by $n+1$.

Let $\gamma_{j}(p), j=1 . . N$, be the equilibrium outcome for a specific implementation procedure, given a preference constellation $j$, as defined by Propositions 1 through 3 . We can define the mean distance between the outcomes of the policy implementation game and the ideal point of a player $i$ by

$$
\Delta_{i}(p) \equiv \frac{\sum_{j=1}^{N}\left|\gamma_{j}(p)-P^{j}\right|}{N}
$$

with $\boldsymbol{p}$ being the ideal point of player $i$ in preference constellation $j$.

Normalizing $\delta$ to one, we get the following mean distances and standard deviations (summarized in Table 1) for the difference among the outcomes of the different procedures and the ideal points of the Commission, the median number of the Council,

\footnotetext{
${ }^{21}$ As for the ideal points of the rightmost, median, and leftmost decisive members of the committee, Parliament, or the Council, one could imagine the following way of modeling the distribution of these ideal points: If we assume that the preferences of the $m$ individual members are distributed uniformly on a closed interval, then the probability of the ideal point of the decisive member being at some point $x$ is given by the probability that the ideal points of $n<m$ members are smaller than $x$ and the ideal points of $m-n$ members are greater or equal to $x$, where $n$ or $m-n$ is the number of members who are required to vote for or against a proposal. This probability can easily be calculated using the binomial distribution. In this case the distribution of the ideal points of the decisive members may depend on the size of the body.
} 
and the dummy player, respectively. ${ }^{22}$ The table gives the length of the interval over which the ideal points can be distributed $(n)$ and the mean distances for the Commission $(a)$, the median member of the council $\left(l_{m}\right)$ and the dummy player $(d)$ for all procedures and different $n$. An increase in $n$ can be interpreted as a wider range over which individual preferences may diverge. In other words, the greater $n$, the greater is the potential for disagreement.

From this table, several implications can be drawn. ${ }^{23}$

- For all $n$, the three "comitology" procedures convey a different amount of power to the Commission. The mean distance between the outcomes of the implementation games and the preferred policy of the Commission is smallest in the management committee procedure and largest in the regulatory committee veto procedure. Given these results, the Commission's preference over different procedures can be written as: $($ management committee) $>$ (regulatory committee: amendment) $>$ (regulatory committee: veto)

- The difference in Commission power between the management procedure and the amendment version of the regulatory committee procedure results from the fact that both procedures differ with respect to the consequences of an undecided committee. Whereas in the management committee procedure a qualified majority is required to open the gates, in the regulatory committee procedure the committee must be able to form a qualified majority for keeping the gates closed. The difference in Commission power between the veto version and the amendment version of the regulatory committee procedure results from the fact that the Commission is restricted in the veto version by the possibility that the Council may veto the Commission proposal in favor of the status quo ante.

- For all $n$, the three "comitology" procedures also confer a different amount of power on the Council. The mean distance is smallest for the veto version of the regulatory procedure and is largest for the management procedure. Given these results, the Council's preference over different procedures can be written as: (management committee) < (regulatory committee: amendment) < (regulatory committee: veto)

- Surprisingly, from a minimum range of potential disagreement $(n=4)$ in the management committee procedure, the median Council member performs worse than a completely powerless dummy player. This counter-intuitive result is due to the fact that the median Council member in the management committee procedure does not affect the outcome directly. Due to our assumption that $a \geqslant L_{m}$, the restriction that the policy chosen will be in $\left[L_{m}, \max \left\{L_{r}, C_{r}\left(L_{r}\right)\right\}\right]$ does not imply any binding restriction imposed by the median Council member. While the preferences of the dummy player may vary freely over all possible preference constellations, the preferences of

\footnotetext{
${ }^{22}$ Note that we can interpret the values defined with respect to the ideal point of the median member of the Council as a useful measure for the power of the Council even if the identity of the median member is not the same for all possible preference constellations. Suppose that without the delegation of implementation power to the Commission, followed by the use of one of the comitology procedures, the Council itself would decide with simple majority on the policy to be implemented. In this case, the ideal point of the median member of the Council determines the outcome. Thus, regardless of the identity of the median member, the mean distance captures the difference between the best outcome that a Council not delegating implementation power could guarantee and the outcome that results from the use of a specific procedure.

${ }^{23}$ We want to stress that neither the absolute nor the relative change in the respective power should be generalized, because the figures are highly sensitive to the assumption about the probability of different preference constellations. Thus, we want to consider only implications drawn from the direction of change.
} 
the median Council member must always satisfy $L_{l} \leqslant L_{m} \leqslant L_{r}$. This restriction on the range of ideal points for the median Council member implies the bias against $l_{m}$ in cases where he has no effect on the actual outcome, as compared to a powerless player without any restriction on his ideal points. This bias becomes more effective if the range of possible ideal points increases.

- The dummy player represents an agent who, though not involved in the decisionmaking process, is affected by its outcome. Under the assumption that the members of the European Parliament have preferences that satisfy the same assumptions as the preferences of those players actively involved in the implementation game, the figures given for the dummy player can be interpreted as representing the position of the European Parliament (represented by the ideal point of one of its members). Even if the dummy player is not involved in the game, at least for a sufficiently large potential for disagreement $(n \geqslant 3)$ he is better off under the regulatory committee procedures. For still larger potential for disagreement $(n \geqslant 4)$, the veto version is better for the dummy player than the amendment version. This can be interpreted as a result of actual outcomes being less biased in favor of the Commission's ideal point, as the figures for the Commission show. Being a dummy player under current implementation procedures, the European Parliament clearly has an incentive to change these procedures and become more closely involved in these decision-making processes. One way to change procedures is to propose and introduce a formal role for Parliament at the implementation stage. Another possibility is that Parliament, which may review the policy initiatives of the Commission (and dismiss the Commission with a two-thirds majority vote), uses its current powers to affect common policies.

\section{Conclusion}

We have shown how the results of a policy-setting game, by which the outcomes of legislative processes are put into effect, depend on the procedures used for the implementation of a policy. We have analyzed three prominent procedures laid down in the comitology decision. To compare these procedures, we have tried to focus on the power of the Commission in setting the policy that best suits its own interests. Our main findings are that-besides the advisory committee procedure, which does not restrict the Commission in the slightest way ${ }^{24}$ - the management committee procedure restricts the Commission the least. Under this implementation procedure, the Commission has the most power in setting public policies. The Council would rank the current implementation procedure differently, that is, it would prefer the veto variant of the regulatory committee procedure most.

Furthermore, one could ask how the balance of power would change if the Parliament were involved at the implementation stage. Presumably, an involvement of Parliament would reduce the power of the Commission to set a policy according to its own preferences. This effect may depend crucially on the extent to which the preferences of the Commission and of the members of Parliament are correlated. Possibly, both the Commission and the European Parliament may prefer an institutional arrangement, where the role of Parliament is more to restrict the influence of the Council and the committees rather than to actively propose or amend policies itself.

We have presented a positive analysis of existing procedures governing the policy

\footnotetext{
${ }^{24}$ This result has not been proved in the paper, but given the description of the advisory committee procedure from Section III, it should be straightforward.
} 
implementation stage, and it seems necessary to stress that "more" or "less" power for the Commission does not necessarily coincide with "better" or "worse" decisionmaking procedures. The latter judgment has to be kept for a normative analysis. For this kind of analysis, of course, one needs a normative criterion to judge the quality of different procedures in terms of their outcomes. Such a criterion would have to acknowledge that none of the institutional players should be seen as an end in itself, but rather that all of them are intended to serve the interest of the European citizens. Thus, the normative criterion would have to judge how well the preferences of the European citizens are represented in the policies that are selected at the European level.

Quite naturally, one would expect that these preferences are mirrored in the composition of the European Parliament, and thus, are best reflected in the preferences of the parliamentary players. Consequently, a decision procedure that does not allow for some influence of the Parliament seems, at first sight, to be worse than procedures where the outcome is affected by parliamentary players. This conclusion, however, rests on the assumption that the preferences of these parliamentary players in fact reflect the preferences of the citizens better than the preferences of other players. These preferences are not completely exogenous, but depend on the way the members of the different bodies are appointed and on their responsibility to the electorate of the individual member states. If the interests of the European electorate are highly valued, then the European Parliament needs to play a more substantial role in the implementation process. ${ }^{25}$ On the other hand, if the interests of the national electorate or the regions are regarded as important, particularly in a pursuit of European integration, the Council or an adapted voting body based on a regional representation of interest and not on proportionality, should be the player who is most likely to determine the outcome of an implementation process.

An answer to the question of whether and how well the individual players' preferences reflect the preferences of the citizens needs further institutional analysis. The extent to which the preferences of the electorate are represented by some of the players in the policy game does not convey much information, however, without knowing to what extent these players affect the outcome of this game. Our paper focused on the latter question, and can, thus, be regarded as one building block for an analysis of the democratic quality of a European institutional framework, or, in a broad sense, a European constitution.

\section{Appendix}

\section{Notation}

The following notation is used in this paper:

$i$ player ( $a$ : Commission, $d$ : dummy player, $c$ : member of a committee of representatives, $l$ : member of the Council).

$i_{l} \quad$ leftmost member of a committee (in the technical sense, i.e., the Council or a committee of representatives), who finds to his right the ideal points of other members whose vote shares constitute a qualified majority, including its own vote share $(i \in\{c, l\})$.

\footnotetext{
${ }^{25}$ We will address this question in a companion paper, analyzing hypothetical procedures with parliamentary involvement.
} 
$i_{m} \quad$ median member of a committee in the above sense $(i \in\{c, l\})$.

rightmost member of a committee in the above sense, who finds to his left the ideal points of other members whose vote shares constitute a qualified majority, including his own vote share $(i \in\{c, l\})$.

$q \quad$ status quo ante.

$I \quad$ player $i$ 's ideal point $\left(I \in\left\{A, L_{m}, L_{r} C_{b}, C_{n}, D\right\}\right)$.

$I(q) \quad$ player $i$ s point of indifference to $q$.

$P_{i} \quad$ strict preference set of player $i$.

$R_{i} \quad$ weak preference set of player $i$.

$S_{i} \quad$ qualified majority coalition of members of a committee $j$ of which $i$ is the leftmost or rightmost member.

$\gamma_{j}(p) \quad$ outcome of procedure $p$ given preference constellation $j$.

$\delta$ minimum distance between two possible ideal points.

$n \quad$ multiplier determining the interval length over which the ideal points can be distributed in multiples of $\delta$.

$N \quad$ number of feasible preference constellations (including ideal points and status quo ante).

$\Delta_{i}(p) \quad$ mean distance between the outcomes of a policy implementation game defined by procedure $p$ and the ideal point of player $i$.

\section{Proof of the Propositions}

Proof of Proposition 1. Note that for $x \geqslant L_{m}$, the set $M$ is equivalent to $\left[L_{m}, L_{r}\right]$. For $x \leqslant L_{r}$, the Council selects $y=x$, and the gatekeeper will not open its gates, since any other action will lead to a lower payoff. The Commission, with an ideal point $A \leqslant L_{r}$ selects $x=A$. More interesting cases occur when the Council proposes $y=L_{r}$, that is, if $x>L_{r}$. Now, three cases need to be distinguished:

(a) If $C_{r}<L_{r}, C_{r}$ is the relevant decisive committee member, and $C_{r}\left(L_{r}\right)<C_{r}<L_{r} R_{S_{r}^{c}}\left(L_{r}\right)$ is non-empty and equivalent to $\left[C_{r}\left(L_{r}\right), L_{r}\right]$. However, for $x \geqslant L_{m}, R_{S_{r}^{c}}\left(L_{r}\right) \subseteq M$, and the gatekeeper will always keep its gates closed given the response of the Council.

(b) If $C_{l} \leqslant L_{r} \leqslant C_{r}$, the committee opens its gates when $x>C_{r}\left(L_{r}\right)$. Then, its decisive member $r$ strictly prefers $y$ to $x$. Only if $x \leqslant C_{r}\left(L_{r}\right)$, and thus $x \in G\left(L_{r}\right)$, the gatekeeper cannot reach a decision and keeps its gates closed. Note that $G\left(L_{r}\right)$ is equivalent to $\left[C_{l}\left(L_{r}\right), C_{r}\left(L_{r}\right)\right]$, with $C_{l}\left(L_{r}\right) \leqslant L_{r}$ so $M$ and $G\left(L_{r}\right)$ have a non-empty intersection.

(c) If $C_{l}>L_{n}, C_{l}$ is decisive. The committee keeps its gates closed either if $x \in R_{S_{l}^{c}}\left(L_{r}\right)$, or $x \in G\left(L_{r}\right)$. Since $R_{S_{l}^{c}}\left(L_{r}\right)$ is equivalent to $\left[L_{r} C_{l}\left(L_{r}\right)\right]$, and $G\left(L_{r}\right)$ to $\left[C_{l}\left(L_{r}\right), C_{r}\left(L_{r}\right)\right]$, its union is $\left[L_{r}, C_{r}\left(L_{r}\right)\right]$.

The Commission selects its best $x$ such that the gatekeeper does not open its gates. The set of points that satisfy this condition is equivalent to $\left[L_{m}, L_{r}\right]$ for $C_{r}<L_{r}$ or $\left[L_{m}, C_{r}\left(L_{r}\right)\right]$ for $C_{r} \geqslant L_{r}$. The equilibrium policy will be: $x=A$ for $L_{m} \leqslant A \leqslant \max \left\{L_{n} C_{r}\left(L_{r}\right)\right\}$, or $x=$ $\max \left\{L_{r}, C_{r}\left(L_{r}\right)\right\}$ for $A>\max \left\{L_{r}, C_{r}\left(L_{r}\right)\right\}$.

Proof of Proposition 2. See Proposition 1. For $x \geqslant L_{m}$, three cases need to be distinguished:

(a) If $C_{r}<L_{r}$, as before, the gatekeeper will keep its gates closed;

(b) If $C_{l} \leqslant L_{r} \leqslant C_{r}$ the committee cannot form a qualified majority in favor of $x$ given 
$y$, since $P_{\mathrm{S}_{\mathrm{r}}^{\mathrm{c}}}(y)=\emptyset$ and $P_{S_{l}^{c}}(y)=\emptyset$. Consequently, the committee will only keep its gates closed when $x \in M$ :

(c) If $C_{l}>L_{r}, C_{l}$ is the decisive committee member. Now, the committee will not open its gates when $x \in R_{C_{t}}\left(L_{r}\right)$.

The Commission selects its best $x$ such that the gatekeeper does not open its gates. The set of points that satisfy this condition is equivalent to $\left[L_{m}, L_{r}\right]$ for $C_{l}<L_{n}$ or $\left[L_{m}, C_{l}\left(L_{r}\right)\right]$ for $C_{l} \geqslant L_{r}$. The equilibrium policy will be: $x=A$ for $L_{m} \leqslant A \leqslant \max \left\{L_{r}, C_{l}\left(L_{r}\right)\right\}$, or $x=$ $\max \left\{L_{r}, C_{l}\left(L_{r}\right)\right\}$ for $A>\max \left\{L_{r}, C_{l}\left(L_{r}\right)\right\}$.

Proof of Proposition 3. For $q \geqslant L_{r}$ see Proposition 2. The Council will not veto the Commission proposal $x$ since $L_{m}$ prefers $y=x$ for $x \leqslant L_{r}$ or $y=L_{r}$ for $x>L_{r}$. For $q<L_{r}$ and $q \geqslant L_{m}$, the set of proposals that will not be vetoed is $\left[L_{m} q\right]$. Now, three cases need to be distinguished:

(a) If $C_{r}<q$, the gatekeeper weakly prefers proposals in $R_{S_{r}}(q)=\left[C_{r}(q), q\right)$. However, these proposals are also veto-proof proposals, i.e., will be accepted by the Council, so the gatekeeper will keep its gates closed;

(b) If $C_{l} \leqslant q \leqslant C_{n} R_{S_{i}}(q)=\varnothing$ and $R_{S_{r}^{c}}(q)=\varnothing$, so the committee cannot form a qualified majority in favor of $x$ given $q$. The committee will only keep its gates closed when $x$ is veto-proof, that is, $x \leqslant q$;

(c) If $C_{l}>q, R_{S_{l}^{c}}(q) \neq \emptyset$. $C_{l}$ is the decisive committee member. Now, the committee will not open its gates when $x \in R_{C_{l}}(q)$, which is equivalent to $\left(q, C_{l}(q)\right]$.

The Commission selects its best $x$ such that the gatekeeper does not open its gates. The set of points that satisfy this condition is equivalent to $\left[L_{m}, q\right]$ for $C_{l} \leqslant q$, or $\left[L_{m}, C_{l}(q)\right]$ for $C_{l}>q$. The equilibrium policy will be: $x=A$ for $L_{m} \leqslant A \leqslant \max \left\{C_{l}(q), q\right\}$, or $x=$ $\max \left\{C_{l}(q), q\right\}$ for $A>\max \left\{C_{l}(q), q\right\}$.

Similarly, the solutions for $q \leqslant L_{m}$, and therefore $L_{m}(q)>L_{m}$, can be derived.

\section{References}

BLACK D. (1987 [1958]). The Theory of Committees and Elections, Boston: Kluwer.

CoOter, R., and DrexL, J. (1994). The logic of power in the emerging European constitution: Game theory and the division of powers. International Review of Law and Economics. 14:307-326.

EuROPEAN COUNCIL (1987). Council decision of 13 July 1987 laying down the procedures for the exercise of implementing powers conferred on the Commission $(87 / 373 /$ EEC). Official Journal of the European Union, L 197/33.

KAPTEYN, P.J.G., and VeRLOREN VAN THEMAAT, P. (1990). Introduction to the Law of the European Communities: After the Coming into Force of the Single European Act, Deventer: Kluwer.

MOSER, P. (1995). The European parliament as a conditional agenda setter: What are the conditions? University of St. Gallen. mimeo.

STEUNENBERG, B. (1994a). Regulatory policymaking in a parliamentary setting. In P. HeRDER-DORNEICH, K-E. SCHENK, and D. SCHMIDTCHEN (Eds.), Jahrbuch für Neue Politische Ökonomie, Band 13. Tübingen: Mohr. 36-57.

SteunenberG, B. (1994b) Decision making under different institutional arrangements: Legislation by the European community. Journal of Institutional and Theoretical Economics. 150:642-669.

Tsebelis, G. (1994). The power of the European parliament as a conditional agenda setter. American Political Science Review. 88:128-142. 